
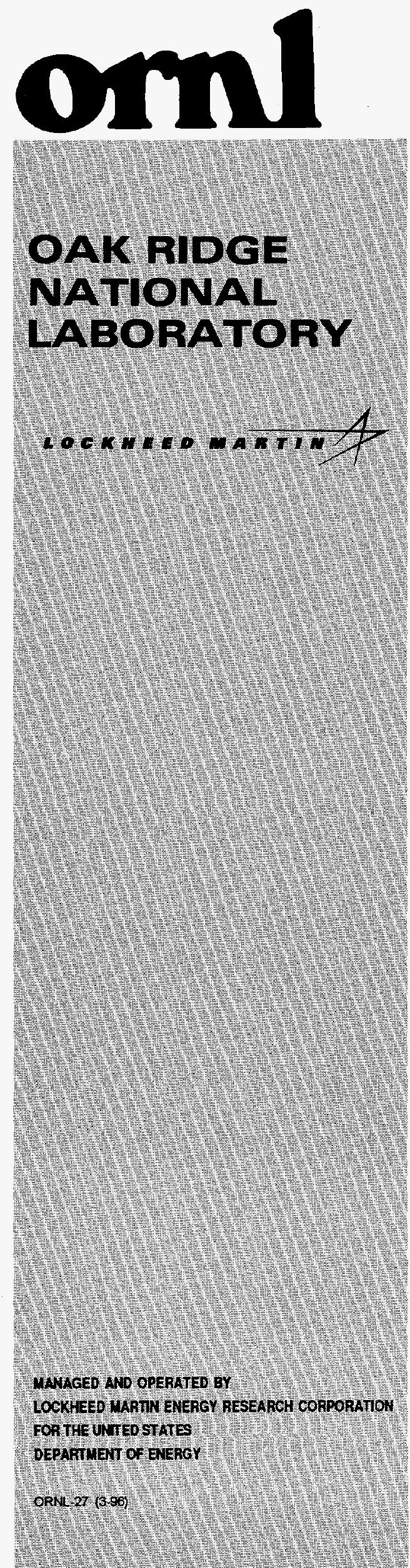

\title{
Nuclear Data to Support Computer Code Validation
}

\author{
S. E. Fisher \\ B. L. Broadhead \\ M. D. DeHart \\ R. T. Primm III
}

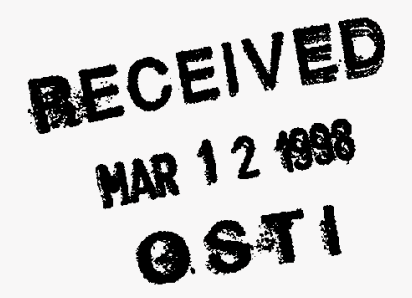


This report has been reproduced directly from the best available copy.

Available to DOE and DOE contractors from the Office of Scientific and Technical information, P.O. Box 62, Oak Ridge, TN 37831; prices available from (423) 576-8401.

Available to the public from the National Technical Information Service, U.S. Department of Commerce, 5285 Port Royal Rd., Springfield, VA 22161.

This report was prepared as an account of work sponsored by an agency of the United States Government. Neither the United States Government nor any agency thereof, nor any of their employees, makes any warranty, express or implied, or assumes any legal liability or responsibility for the accuracy, completeness, or usefulness of any information, apparatus, product, or process disclosed, or represents that its use would not infringe privately owned rights. Reference herein to any specific commercial product, process, or service by trade name, trademark, manufacturer, or otherwise, does not necessarily constitute or imply its endorsement, recommendation, or favoring by the United States Government or any agency thereof. The views and opinions of authors expressed herein do not necessarily state or reflect those of the United States Government or any agency thereof. 


\section{DISCLAIMER}

Portions of this document may be illegible electronic image products. Images are produced from the best available original document. 
ORNL/TM-13422

Dist. Category UC-523

\title{
NUCLEAR DATA TO SUPPORT COMPUTER CODE VALIDATION
}

\author{
S. E. Fisher \\ B. L. Broadhead \\ M. D. DeHart \\ R. T. Primm III
}

Date Published: April 1997

Prepared by the

OAK RIDGE NATIONAL LABORATORY

Oak Ridge, Tennessee 37831

managed by

LOCKHEED MARTIN ENERGY RESEARCH CORP.

for the

U.S. DEPARTMENT OF ENERGY under contract DE-AC05-96OR22464 
Page Intentionally Blank 


\section{CONTENTS}

Page

PREFACE

1. INTRODUCTION

2. REACTOR CORE PHYSICS CALCULATIONS

2.1 DOMESTIC (U.S.) PRESSURIZED-WATER REACTORS

2.2 DOMESTIC (U.S.) BOILING-WATER REACTORS .

2.3 QUAD CITIES MOX IRRADIATION TEST PROGRAM.

2.4 QUAD CITIES MEASUREMENTS AND TESTS (APPLICABLE TO POSSIBLE REACTOR PHYSICS BENCHMARKS)

2.4.1 Gamma Scans

2.4.2 Gadolinia Depletion

2.4.3 Cold Critical Measurements (Performed at the Start of Cycle 4)

2.4.4 Isotopic Determinations

2.4.5 Burnup Gamma Scans (Linear Heat Generation Rate)..

2.5 BENCHMARK RECOMMENDATIONS

3. OUT-OF-CORE PHYSICS ANALYSES .

3.1 CRITICALITY SAFETY

3.2 RADIATION SHIELDING.

3.3 RECOMMENDED APPROACHES TO SHIELDING ANALYSIS

3.3.1 Unirradiated Fuel

3.3.2 Irradiated Fuel

3.3.3 Irradiated Fuel Source Terms.

3.3.4 Spent Fuel Shielding Recommendations 
Page Intentionally Blank 


\section{PREFACE}

This document is one in a series of topical reports written in support of the U.S. Department of Energy's (DOE's) Program Acquisition Strategy for Obtaining Mixed-Oxide Fuel Fabrication and Reactor Irradiation Services (PAS) [formerly Procurement Implementation Plan for Acquisition of Mixed-Oxide Fuel Fabrication Services and Reactor Irradiation Services (PIP)]. This series of topical reports is intended to increase access to available information for parties interested in responding to PAS and the subsequent request for proposal. These topical reports address subjects relevant to DOE's strategy concerning disposition of surplus plutonium by irradiating mixed-oxide (MOX) fuel in existing, domestic commercial reactors. This report presents sources of neutronics measurements that have the potential application for validating MOX fuel cycle calculations. 


\section{INTRODUCTION}

The rate of plutonium disposition will be a key parameter in determining the degree of success of the Fissile Materials Disposition Program. Estimates of the disposition rate are dependent on neutronics calculations. To ensure that these calculations are accurate, the codes and data should be validated against applicable experimental measurements. Further, before mixed-oxide (MOX) fuel can be fabricated and loaded into a reactor, the fuel vendors, fabricators, fuel transporters, reactor owners and operators, regulatory authorities, and the Department of Energy (DOE) must accept the validity of design calculations. This report presents sources of neutronics measurements that have potential application for validating reactor physics (predicting the power distribution in the reactor core), predicting the spent fuel isotopic content, predicting the decay heat generation rate, certifying criticality safety of fuel cycle facilities, and ensuring adequate radiation protection at the fuel cycle facilities and the reactor. The U.S. in-reactor experience with MOX fuel is first presented, followed by information related to other aspects of the MOX fuel cycle. The European experience has undoubtedly generated a vast amount of MOX fuel performance information that is valuable to this program, but the data base remains largely proprietary. Thus, this information is not reported here. It is expected that the selected consortium will make the necessary arrangements to procure or have access to the requisite information.

\section{REACTOR CORE PHYSICS CALCULATIONS}

\subsection{DOMESTIC (U.S.) PRESSURIZED-WATER REACTORS}

The early program associated with the use of MOX in pressurized-water reactors (PWRs) started with a series of irradiations in the Saxton reactor. Westinghouse provided 9 lead test assemblies (LTAs), containing a total of $638 \mathrm{MOX}$ rods, which were loaded into the reactor in 1965. The testing proceeded for a number of cycles, with later reconstitution of $250 \mathrm{MOX}$ rods. A peak pellet burnup of $51 \mathrm{GWd} / \mathrm{MT}$ was achieved. Postirradiation of the rods was carried out, and Westinghouse obtained a great deal of experience from this irradiation. ${ }^{1}$

The U.S. PWR MOX experience continued with the placement of 4 (14-by-14) LTAs in the San Onofre Unit 1 reactor. A total of 720 MOX rods was placed in 4 LTAs, and all rods in the bundles were MOX. High fissile plutonium ( $86 \%)$ was used in this irradiation. These LTAs were placed in cycle 2 . At the end of cycle 2, 52 removable rods (from two bundles) were inspected. However, only 48 MOX rods were replaced, and 4 urania rods were reconstituted in the bundle. The four LTAs were irradiated during cycle 3 and removed. They operated with a peak linear heat rate of $7.3 \mathrm{~kW} / \mathrm{ft}$ to a peak pellet burnup of $25.2 \mathrm{GWd} / \mathrm{MT}$. Postirradiation information obtained from this examination may be available from Westinghouse and is also probably contained in Electric Power Research Institute (EPRI) reports (but it has not been located).

The most recent U.S. PWR irradiation experience with MOX involves 4 (14-by-14) "all-MOX" LTAs that were irradiated in the Ginna reactor. These rods were initially stored at the Cheswick, Pennsylvania. facility starting in 1974. Four MOX assemblies were inserted in the core and irradiated for five cycles. An average assembly burnup of $\sim 38 \mathrm{GWd} / \mathrm{MT}$ was achieved. Based on the U.S. experience to date (and because of the current lack of information concerning the San Onofre irradiations), the Ginna irradiations are considered to be the best available source for PWR core physics data.

The four MOX bundles were inserted in the Ginna reactor in May 1980 at the beginning of cycle 10 . The bundles were located at the core periphery for the first cycle. These bundles were discharged in March 1985 after five cycles of irradiation. The all-MOX bundles consisted of "high-enrichment" (3.279 wt \%, uranium plus plutonium fissile) rods in the central portion, surrounded by "medium-enrichment" rods ( $3.090 \mathrm{wt} \%$ fissile), with "low-enrichment" ( $2.736 \mathrm{wt} \%$ fissile) rods at the corners. There was an instrumentation tube near the center of the bundle. ${ }^{2,3}$

LTAs were taken to high burnups ${ }^{4}$ (a range from 38,600 to $39,800 \mathrm{MWd} / \mathrm{MT}$ ). No fuel failures were found, and Ref. 3 cites nonproliferation reasons for irradiating these assemblies. Little information has been found concerning what core locations these assemblies occupied. Because the Nuclear Regulatory 
Commission (NRC) requires semiannual fuel accountability information (for uranium, plutonium, etc.), there is little doubt that the history of these assemblies could be reconstituted. No fuel failures were noted, and the best information to date is that the assemblies are still in the storage pool at the Ginna site. No destructive examinations of the rods were carried out.

\subsection{DOMESTIC (U.S.) BOILING-WATER REACTORS}

The early program associated with the use of MOX in boiling-water reactors (BWRs) started with a series of irradiations in the Vallecitos BWR. The testing was conducted with rods containing plutonium generated through irradiation in the Dresden reactor. Documentation found to date is insufficient to qualify these irradiations as benchmarks.

Four MOX bundles, containing a single MOX rod per bundle (containing Dresden self-generated plutonium), were inserted into Dresden 1 in 1967. Because of the limited scope, the small amounts of MOX that were employed, and the fact that later irradiation data from other reactors were more plentiful, no further investigation of the Dresden irradiations was undertaken.

The start of an extensive series of domestic BWR irradiations in the Big Rock Point Reactor (BRP) commenced with the loading of 16 bundles (each containing 2 MOX rods) in May 1969. General Electric (GE) and Exxon Nuclear fabricated bundles for BRP. BRP was considered to be a test bed for MOX fuel during the mid-1970s. Plutonium concentrations ranged from 1.2 to $9.1 \mathrm{wt} \%$ with burnups performed in excess of $30 \mathrm{GWd} / \mathrm{MT}$. Some BRP rods were ramp-tested (transient power excursions).

The BRP license allowed the loading of up to $50 \mathrm{~kg}$ of plutonium. Irradiations at BRP encompassed the greatest variation in MOX fuel designs. According to Ref. 1, Consumer's Power loaded 18 (Exxon Nuclear) 11-by-11 bundles, each containing 24 MOX rods, in 1974. Eight additional MOX (Exxon Nuclear) bundles were loaded in 1976. However, according to Ref. 2, the sequential loading of MOX rods (produced by Exxon Nuclear) consisted of 2, 6, 12, 8, and 14 of the 11-by-11 bundles.

Extensive testing using an "island" design concept-MOX rods in the center of the fuel assembly surrounded by uranium rods-was performed in the Quad Cities-1 reactor. Initially, the Vermont Yankee reactor was scheduled to be the host reactor for these irradiations. However, because of licensing issues, the fuel was redesigned and modified for insertion into the Quad Cities-1 reactor. A license to operate the MOX fuel was granted to Commonwealth Edison in June 1974, and five assemblies were inserted into Quad Cities at the beginning of cycle 2. The Quad Cities irradiation constitutes the most recent BWR testing of MOX fuel in the United States. The information that has been currently reviewed also indicates that the most comprehensive fuel testing on BWR fuel was performed on the Quad Cities fuel.

\subsection{QUAD CITIES MOX IRRADIATION TEST PROGRAM}

The loading arrangement for cycle 2 contained 660 fresh low-enriched uranium (LEU) 7-by-7 bundles, 23 of the 7-by-7 LEU reload bundles, 36 of the 8-by-8 LEU reload bundles, and 5 MOX 7-by-7 bundles. The five bundles began operation July 21,1974 . A total of 48 MOX fuel rods was initially placed into the core. Four (GEB158, 159, 160, and 161, each containing 10 MOX rods) of the five bundles were placed around the center control rod and operated there until discharge (although several reconstitutions were performed). A fifth bundle (GEB162), containing eight rods, was located at the core periphery. This edge-loaded assembly provided information for a low-power, hard neutron flux environment for the MOX fuel. In addition, information for such effects as leakage, thermal flux gradient, and flow conditions at the reflector were provided.

The 48 rods contained $80-90 \%$ fissile $\mathrm{PuO}_{2}$ derived from recycled Dresden 1 fuel and United States Atomic Energy Commission (USAEC) material (the isotopics are given on p. 12-10 of Ref. 5). Four enrichments were used, 2.34 and $3.62 \mathrm{wt} \%$ plutonium fissile for hollow pellets and 2.14 and $3.52 \mathrm{wt} \%$ plutonium fissile for solid pellets. Five gadolinium oxide rods were used in the central bundles to increase the shutdown margin.

During cycle 2, the control rod was fully withdrawn in the latter part of the cycle. Following the completion of cycle 2, nine fuel rods from GEB161 and six rods from GEB 162 were discharged for destructive examinations. Rods were shuffled between bundles, some shuffled within bundles, and 15 fresh $\mathrm{UO}_{2}$ rods 
were inserted to replace the discharged rods. Five rods from each of bundles GEB158 and GEB 159 were swapped, and all of the $\mathrm{UO}_{2}$ rods under surveillance from the central bundles were placed into one bundle. ${ }^{5}$

The five bundles were irradiated in cycle 3. There were some control rod effects on the MOX assemblies since the control blade was left one-third inserted during the last $60 \mathrm{~d}$ of the cycle, and these effects were reflected in the measurements. The current documentation ${ }^{6}$ indicates that two MOX bundles (GEB159 and GEB162) were disassembled to perform a gamma scan on some single rods at the end of cycle 3 . Some external mechanical modifications were made at many of the refueling outages but had no effect on the bundle design.

Operating information for cycles $1-3$ is summarized in Refs. 7 and 8 . These operating data reports describe the burnup steps that were taken and cite the axial power distributions measured during the cycle using the traversing in-core probes (TIPs). Operating information for cycles 4 and 5 has not been reviewed but can be found in $\mathrm{GE}$ reports.

At the end of cycle 5, the four central bundles were discharged, and a new bundle designated GEB159 (delta) was reconstituted from rods out of GEB158, GEB159, and GEB161. With respect to the disposition program and individual rod destructive test data, rod VP0017, which is a solid MOX rod, provides some valuable performance data at high burnups.

The reconstituted bundle from EOC 5 was inserted into the previous GEB159 position, and the irradiation period for cycle 6 was carried out. At the end of cycle 6, bundles GEB159 (delta) and GEB 162 (containing MOX fuel rods) were discharged from the reactor. Annular and solid MOX fuel pellets were irradiated in excess of 55,000 MWd/MT, thereby providing high-burnup fuel performance information. The EOC 6 results have not been located in the open literature.

\subsection{QUAD CITIES MEASUREMENTS AND TESTS (APPLICABLE TO POSSIBLE REACTOR PHYSICS BENCHMARKS)}

An overall description of the measurements taken on all of the rods is contained in Ref. 5. The program was quite extensive, encompassing measurements that are valuable from both a reactor physics viewpoint and a materials performance viewpoint. The measurements taken at Quad Cities considered to be applicable (with respect to providing a possible physics-related benchmark) are described in the following sections.

\subsubsection{Gamma Scans}

Gamma scans (bundle and some individual rods) were taken following cycles $2-4$. Cycles 5 and 6 measurements were also performed but under a separate GE program (thus, GE may have a valid claim that the results from these are strictly proprietary). The gamma scan was performed to determine the ${ }^{140} \mathrm{La}$, which is a daughter of ${ }^{140} \mathrm{Ba}$. The ${ }^{140} \mathrm{Ba}$ distribution in the fuel was a characteristic of the last $60 \mathrm{~d}$ of reactor operation. Thus, the primary objective of the scans was to provide a benchmark for the power distribution. Bundles were typically scanned at 12 different elevations and sometimes 24 elevations for greater detail. Individual rod measurements generally covered eight locations and provided pin-to-pin power distribution benchmarks. Three topical reports covered cycles 2, 3, and 4 gamma scan measurements (the first two were EPRI reports; the fourth cycle was described in a GE document-see p. 7-21 of Ref. 5).

Following cycles 2 and 3, all five MOX bundles were scanned. From the existing documentation, it was apparent that bundle scans were performed for EOC 4, but the information concerning individual rod scans was not clear. In addition, one-eighth of the core was scanned to assess the gross power shape and reload bundle power sharing. Rod-to-rod planar power distributions for EOC 2 and EOC 3 and bundles GEB-162 and GEB-159 are shown in Ref. 5. While the EPRI report cites the value of these measurements in terms of an "accurate data base against which power distribution calculations and on-line power measurement systems have been and continue to be compared," 5 the comparison between measurements and calculation has not been found. Perhaps the data exist in the EPRI reports and GE documents referred to above.

More information concerning the EOC (2, 3, and 4) gamma scans is provided in Sect. 12.3.5 of Ref. 5. The axial linear heat generation rate is given for one solid MOX rod and for a number of other rods (annular $\mathrm{MOX}$ and $\mathrm{UO}_{2}$ ) at EOC 2,3, and 4. The comparison of prediction and measurements is given in 
this section. These heat rates are important not only for thermal-hydraulic analyses but also as an input for the predictions of fission-gas release. Additional information is also given in Ref. 6 for the end of cycle 3 measurements.

\subsubsection{Gadolinia Depletion}

Gadolinia was incorporated into a number of the $\mathrm{UO}_{2}$ rods. Gadolinia depletion was measured at the end of cycle 2. Currently, gadolinia depletion is not an issue for the MOX fuel (assuming the island design or $\mathrm{UO}_{2}$ "look-alike" designs are used). However, the widespread use of MOX will change the flux spectra from those found in LEU fuel; thus, the gadolinia burnout in standard $\mathrm{UO}_{2}$ bundles might possibly be called into question.

\subsubsection{Cold Critical Measurements (Performed at the Start of Cycle 4)}

The shutdown margin with the "one-rod-stuck" condition (cold core) is a safety-related condition that must be analyzed and shown to be within an acceptable value. At the start of cycle 4, two full-length flux wires were inserted, and criticality was achieved by two control blade withdrawals. The wires were withdrawn, and an activation analysis was performed. From these two wires a fast flux (from a nickel wire) and a thermal flux axial shape (from a copper wire) were measured. These measurements were compared with calculations and were in good agreement with the calculated value (see Figs. 10-3 and -4, Ref. 5). The calculated eigenvalue was quoted as 1.007 , which was consistent with other calculations performed. ${ }^{5}$ This experiment was conducted because there was some curiosity with respect to how well the diffusion theory code could predict steep flux gradients.

\subsubsection{Isotopic Determinations}

At the end of cycle 2, 15 fuel rods were removed (from two bundles), and isotopic determination measurements were performed on these rods (see pp. 11-3 and -4, Ref. 5). Nine of the rods came from central bundle GEB161 (average burnup of $9160 \mathrm{MWd} / \mathrm{MT}$ ). Eight MOX rods (four solid, four annular) were sampled with two annular and two solid rods from each bundle. The pellet samples were taken at four different axial planes-53.3, 144.8, 236.2, and $327.7 \mathrm{~cm}$ above the bottom of the active fuel. Battelle was responsible for sample preparation, and the GE Vallecitos hot cell facility was used to perform the measurements. Alpha spectroscopy was used to measure ${ }^{237} \mathrm{~Np},{ }^{242} \mathrm{Cm}$, and ${ }^{241} \mathrm{Am}$. Total americium and curium concentrations were also analyzed.

Atom density ratios for ${ }^{235} \mathrm{U},{ }^{239} \mathrm{Pu}$, and ${ }^{241} \mathrm{Pu}$ were measured as a function of burnup. In addition, ${ }^{237} \mathrm{~Np},{ }^{241} \mathrm{Am}$, and ${ }^{242} \mathrm{Cm}$ were measured. The results are documented in Sect. 11 of Ref. 5 . Because only one cycle of irradiation was conducted, only low-burnup value (up to about 13,500 $\mathrm{MWd} / \mathrm{MT}$ ) data were reported. ${ }^{5}$

Radial samples were also taken. The distribution of ${ }^{155} \mathrm{Gd}$ and ${ }^{157} \mathrm{Gd}$, along with ${ }^{235} \mathrm{U}$ depletion, ${ }^{239} \mathrm{Pu}$, and ${ }^{241} \mathrm{Pu}$ buildup is shown (for a $\mathrm{UO}_{2} \mathrm{rod}$ ). Radial power shapes are useful because these shapes influence fission-gas release rates. The detailed mass spectrometric measurements on the gadolinia isotopes are noted as useful for checking cross-sectional libraries.

Specific nuclide information for the EOC 5 measurements has not been found. Except for the information provided in the following sections, the extent of examination is not known.

\subsubsection{Burnup Gamma Scans (Linear Heat Generation Rate)}

One of the solid MOX rods (VP0017, which was loaded with $90 \%$ fissile plutonium) was scanned for gross gamma and ${ }^{137} \mathrm{Cs}$ gamma at the end of cycle 5 . This rod had an average burnup of 35,000 MWd/MT. In addition, fission gas release measurements were made. These provided a benchmark (which found that the annular pellets released more fission gas than the solid pellet) for BWR fuel. Power and temperature history is a significant uncertainty associated with the interpretation of fission-gas measurements. The linear heat generation rate based on measured gamma scans for VP0017 is shown in Figs. 12-3 through 12-5 and Fig. 12-7 (Ref. 5). The EPRI report ${ }^{5}$ states that fine mesh power histories would be desirable for 
comparison with the measured data. In addition to gross gamma scans, data are also presented for ${ }^{137} \mathrm{Cs}$, which is a measure of burnup.

\subsection{BENCHMARK RECOMMENDATIONS}

Regardless of the reactor type selected to accomplish the disposition mission, the experience gained in the Ginna and Quad Cities irradiations will take on more importance as submittals are made to the NRC for LTA irradiations and subsequent reload approvals. In general, MOX fuel performance technology development in U.S. reactors was halted in the late 1970s and early 1980s. From an overall fuel performance technology standpoint, there is no doubt that fuel performance technology based on international experience will, in many cases, supersede the U.S. experience. However, the U.S. irradiations conducted to date did involve plutonium with a high fissile loading. It is expected that much of the international experience with irradiated plutonium concerns recycled plutonium $\left(>20 \mathrm{wt} \%{ }^{240} \mathrm{Pu}\right.$ ). Some of the U.S. experience with high-fissile-content plutonium will complement the MOX experience base rather than being replaced by the foreign experience if it becomes available. In any event, if the U.S. experience is not cited or used, it is likely that NRC would ask questions concerning what aspects of the U.S. experience are applicable to the disposition program.

\section{OUT-OF-CORE PHYSICS ANALYSES}

Nuclear engineering analyses required for those parts of the fuel cycle external to the irradiation in the reactor core include criticality safety, radiation shielding, decay heat, and nuclide inventory calculations. Benchmark measurements exist to support some of these analyses.

\subsection{CRITICALITY SAFETY}

Five lists summarize documents relevant to the validation of computer codes and data for criticality safety applications for the MOX fuel cycle. The first three $(A-C)$ provide references to critical experiments that are of benchmark quality, grouped by composition for different applications in the MOX fuel cycle. [Note that most of these references describe multiple experiments with variations in configuration or content (e.g., fuel pitch, absorber or reflector material, poison, etc.)]. More than 100 experiments are represented by the references contained in lists $\mathrm{A}-\mathrm{C}$. List $\mathrm{D}$ contains references that describe calculational benchmarks used for intercode comparisons, and list $\mathrm{E}$ provides documents that contain additional relevant information potentially useful in validation for MOX systems. Each set of references is provided below with a brief discussion of the application of the documents in the set.

The references provided in list A describe MOX criticals and would be relevant for validation of fabrication/reprocessing, start-up, storage, and transportation applications. These include both homogenous and lattice configurations.

\section{A. MOX criticals $\left(\mathrm{UO}_{2}\right.$ and $\left.\mathrm{PuO}_{2}\right)$}

A.1 S. R. Bierman and E. D. Clayton, "Critical Experiments with Low-Moderated Homogeneous Mixtures of Plutonium and Uranium Oxides Containing 8, 15, and $30 \mathrm{wt} \%$ Plutonium," Nucl. Sci. Eng., 61, 370-76 (1976).

A.2 S. R. Bierman and E. D. Clayton, "Critical Experiments to Measure the Neutron Poisoning Effects of Copper and Copper Cadmium Plates," Nucl. Sci. Eng., 55, 58-66 (1974).

A.3 S. R. Bierman et al., "Critical Experiments with Concrete-Reflected Fast Test Reactor Pins in Water," Nucl. Technol., 49, 40-46 (1980). 
A.4 B. M. Durst et al., "Critical Experiments with Solid Neutron Absorbers and Water-Moderated Fast Test Reactor Fuel Pins,” Nucl. Technol., 48, 128-49 (1980).

A.5 S. R. Bierman et al., "Critical Experiments with Fast Test Reactor Fuel Pins in Water," Nucl. Technol., 44, 141-51 (1979).

A.6 R. I. Smith and G. J. Konzek, Clean Critical Experiment Benchmarks for Plutonium Recycle in LWRs, EPRI NP-196, Vols. I and II, Electric Power Research Institute, April 1976 and September 1978.

A.7 E. G. Taylor et al., Saxton Plutonium Program Critical Experiments for the Saxton Partial Plutonium Core, WCAP-3385-54, Westinghouse Electric Corp., Atomic Power Division, December 1965.

A.8 S. R. Bierman, Criticality Experiments with Fast Test Reactor Fuel Pins in Organic Moderator, PNL-5803, Battelle Pacific Northwest Laboratory, December 1986.

A.9 S. R. Bierman et al., Criticality Experiments with Low-Enriched $\mathrm{UO}_{2}$ Fuel Rods in Water Containing Dissolved Gadolinium, PNL-4976, Battelle Pacific Northwest Laboratory, February 1984.

A.10 V. O. Uotinen, J. H. Lauby, L. C. Schmid, and W. P. Stinson, "Lattices of Plutonium-Enriched Rods in Light Water-Part I: Experimental Results," Nucl. Technol., 15, 257-71 (1972).

Set B contains references for experiments performed based on mixed nitrates. These criticals are all in solution form, in various simple geometries, and would be useful in the validation of aspects of fabrication and processing operations.

\section{B. Mixed-nitrate criticals (plutonium-uranium nitrate solutions)}

B.1 R. C. Lloyd and E. D. Clayton, Summary of Criticality Data Obtained at Battelle Pacific Northwest Laboratories on Fixed and Soluble Poisons in $U+P u$ Nitrate Solutions, BNWL-B-482, Battelle Pacific Northwest Laboratory, April 1976.

B.2 U. P. Jenquin et al., Benchmark Experiments to Test Plutonium and Stainless Steel Cross Sections, PNL-2273, Battelle Pacific Northwest Laboratory, June 1978.

B.3 R. C. Lane and C. Parker, Measurement of the Critical Size of Solutions of Plutonium and Natural Uranium Nitrates at Pu/U $=0.3$, AWRE 058/73, United Kingdom Atomic Energy Authority, December 1973.

B.4 R. C. Lloyd et al., "Criticality of Plutonium-Uranium Mixtures Containing 5 to 8 wt \% Plutonium," Nucl. Sci. Eng., 55, 51-57 (1974).

B.5 R. C. Lloyd and E. D. Clayton, "Criticality of Plutonium-Uranium Nitrate Solutions," Nucl. Sci. Eng., 60, 143-46 (1976).

Set $\mathrm{C}$ provides references for three plutonium-only criticals that may be useful in validating plutonium cross sections; however, these criticals will only be of use if the neutron spectrum is similar to that expected in the various phases of the MOX fuel cycle.

\section{Plutonium-only criticals}

C.1 U. P. Jenquin et al., Benchmark Experiments to Test Plutonium and Stainless Steel Cross Sections, PNL-2273, Battelle Pacific Northwest Laboratory, June 1978. 
C.2 R. C. Lloyd et al., "Criticality Studies with Plutonium Solutions," Nucl. Sci. Eng., 25, 165-73 (1966).

\section{C.3 See also Ref. A.10.}

Set $\mathrm{D}$ lists references that describe calculational benchmarks used for intercode comparisons. These are not true critical experiments per se, but they provide a well-defined basis for which specific aspects of criticality codes and data can be tested. Note that agreement with other codes does not in and of itself provide validation for a particular application; however, agreement with codes that have been properly validated can increase the confidence in the code and/or data for which the comparison is being made.

\section{Calculational benchmarks}

D.1 G. E. Whitesides ed., Standard Problem Exercise on Criticality Codes for Dissolving Fissile Oxides in Acids, NEACRP-L-306, Martin Marietta Energy Systems, Inc., Oak Ridge National Laboratory, April 1990.

D.2 A. Santamarina and H. J. Smith, Analysis of the OECD/NEACRP Problem No. 20 on International Criticality Codes for Fuel Pellets in Fissile Solutions, NEACRP-L-320, Criticality Calculations Working Group, OECD/NEA Committee on Reactor Physics, Organization for Economic Cooperation and Development (1990).

Finally, list E contains four documents relevant to the general knowledge base for MOX applications and validation techniques. The first describes some of the theoretical and computational aspects of lightwater reactor (LWR) MOX lattices; the second and third are a collection of critical benchmarks covering a wide range of compositions, spectra, and configuration. These documents were not included in lists A-C because they (1) contain many criticals that are not directly applicable in MOX applications and (2) may contain criticals that are already described in the earlier references. However, the documents may include additional criticals not referenced earlier or may serve well as a semi-independent companion description of the earlier criticals. The final reference provides a summary of fresh fuel critical experiments that are representative for burnup credit applications and may be useful in MOX applications; this includes descriptions of critical experiments and input listings for SCALE models of the criticals. The criticals included in the report are both $\mathrm{UO}_{2}$-only and MOX criticals, although all MOX criticals are included in previously listed references of this document. More important, this report describes and demonstrates methods for statistical analysis of sets of critical calculations that can be used to determine calculational biases and uncertainties in the code system used.

\section{E. Other relevant documents}

E.1 R. C. Liikala et al., "Lattices of Plutonium-Enriched Rods in Light Water-Part II: Theoretical Analysis of Plutonium-Fueled Systems," Nucl. Technol., 15, 272-96 (1972).

E.2 NEA Nuclear Science Committee, International Handbook of Evaluated Criticality Safety Benchmark Experiments, NEA/NSC/DOC(95)03, Vols. I-VI, Organization for Economic Cooperation and Development, 1995.

E.3 Cross Section Evaluation Working Group Benchmark Specifications, BNL-19302 (ENDF-202), Brookhaven National Laboratory, November 1974.

E.4 M. D. DeHart and S. M. Bowman, Analysis of Fresh Fuel Critical Experiments Appropriate for Burnup Credit Validation, ORNL/TM-12959, Martin Marietta Energy Systems, Inc., Oak Ridge National Laboratory, 1995. 
There are clear deficiencies in the available benchmarks and some questions concerning applicability. The referenced criticals may not be representative of the composition of MOX materials through the full fuel cycle. Although lattice configurations are included, there is a lack of experimental data that represent expected conditions in transportation and storage applications (i.e., MOX assemblies with interstitial absorber or flux trap regions, cask materials, etc.). Finally, almost all experiments referenced involve fresh fuel. The reactor core irradiations discussed in the previous section are the only sources of data for irradiated fuels. Certainly considerable computational studies and possibly additional measurements will be required if credit is to be taken for burnup in the transportation and/or storage of spent MOX fuel.

\subsection{RADIATION SHIELDING}

This overview will address the radiation protection aspects of unirradiated fuel during fabrication and shipment, irradiated (spent) fuel at the reactor plant, and spent fuel transportation to a processing or storage facility. Pertinent issues for unirradiated and irradiated fuel include

1. radionuclides that are important contributors to the radiation source terms (hence, bearing on compliance with the spent fuel standard as described by the National Academy of Science ${ }^{10}$ );

2. general guidance on what shielding validation measurements have been performed, and what new measurements would be useful for extension to MOX-type fuel; and

3. description and references for possible shielding benchmarks.

The general philosophy of the U.S. regulators is that a reasonable calculational procedure indicating compliance with the regulatory requirements is required to obtain a transport license or certificate of compliance; however, these results should be combined with measurements, where practical, to demonstrate compliance before actual off-site shipments can occur.

\subsection{RECOMMENDED APPROACHES TO SHIELDING ANALYSIS}

\subsubsection{Unirradiated Fuel}

This discussion is largely taken from a shielding guide developed at Oak Ridge National Laboratory (ORNL). Only neutron and gamma radiation will be considered, because $\alpha$ and $\beta$ radiation from these materials are assumed to be absorbed in either the material packaging or the processing equipment. The contributors to the radiation considered herein include radioactive decay, spontaneous fission, and $(\alpha, n)$ processes. There may be a significant neutron source, relative to spontaneous fission, from $(\alpha, n)$ reactions with nonradioactive compound material and trace element impurities in the radioactive material. A large source of low-energy gamma rays may be present due to the Bremsstrahlung radiation from $\beta$ decay, but most low-energy gammas are attenuated by the packaging or processing equipment or by self-shielding of the material itself. Induced fission neutrons and gamma rays in fissile material, resulting from spontaneous fission neutrons, should be included in the analysis. There can also be a small source of secondary gamma rays from neutron interactions with the source and other package materials. Typically, these other possible sources (such as photoneutrons, activation neutrons, and activation gamma rays, etc.) can be neglected.

Weapons-grade plutonium typically consists of more than $90 \%{ }^{239} \mathrm{Pu}$ by weight with a few percent ${ }^{240} \mathrm{Pu}$ and fractions of a percent of ${ }^{238} \mathrm{Pu},{ }^{241} \mathrm{Pu}$, and ${ }^{242} \mathrm{Pu}$. A ${ }^{236} \mathrm{Pu}$ concentration on the order of parts per billion can lead to a significant gamma ray source due to the $2.6-\mathrm{MeV}$ gamma ray from ${ }^{208} \mathrm{Tl}$. The decay of ${ }^{241} \mathrm{Pu}$ can lead to a large gamma ray source from ${ }^{241} \mathrm{Am}$ and, to a lesser extent, from ${ }^{237} \mathrm{U}$. The presence of fluorine, boron, lithium, and beryllium even in trace concentrations in the plutonium can lead to a significant $(\alpha, n)$ source relative to spontaneous fission in plutonium. Oxygen, carbon, and other trace or compound elements can also contribute to an $(\alpha, n)$ source when included with plutonium.

All of the isotopes mentioned above can contribute to doses exterior to packaging or processing equipment. The amount of radiation dose is dependent on the relative isotopic concentrations, the surrounding shielding materials, and the decay time since production/separation of the plutonium. The times of maximum dose rate can vary from a few years to several hundred years, depending on these factors. The 
longer times become significant when a shipping package is also used for long-term storage of the plutonium. On a per nuclide basis, the major gamma ray sources are from the decay chains of ${ }^{236} \mathrm{Pu},{ }^{238} \mathrm{Pu}$, and ${ }^{241} \mathrm{Pu}$; and the major neutron sources are from ${ }^{238} \mathrm{Pu},{ }^{240} \mathrm{Pu}$, and ${ }^{242} \mathrm{Pu}$. Only when the plutonium is almost entirely ${ }^{239} \mathrm{Pu}$ is this isotope a major contributor to the dose rate. For analysis of a plutonium package with a range of possible isotopic concentrations and conservatively subcritical, a conservative shielding model would normally include the least possible amount of ${ }^{239} \mathrm{Pu}$ and the maximum amount of ${ }^{236} \mathrm{Pu},{ }^{238} \mathrm{Pu}$, and ${ }^{241} \mathrm{Pu}$. Transportation packages containing plutonium can easily have exterior dose rates that are a significant fraction of the regulatory limits $(2000 \mu \mathrm{Sv} / \mathrm{h}$ at the package surface), and overly conservative calculational models of these packages may compute dose rates that exceed the limits.

\subsubsection{Irradiated Fuel}

This section will explore the generation of source terms for spent fuel and then discuss the use of this source information for both at-reactor and away-from-reactor shielding situations. The at-reactor situations are typically bare-assembly-in-water scenarios, while the away-from-reactor scenarios are typically dry assemblies contained inside a large, heavily shielded cask.

\subsubsection{Irradiated Fuel Source Terms}

In theory, the prediction of isotopics and, hence, the source term for irradiated fuel can be quite difficult because of isotopic variations radially and axially over a fuel assembly as well as variations from assembly to assembly within the reactor. In practice, simplified methods such as those implemented in the ORIGEN2 (Ref. 11) and ORIGEN-S (Ref. 12) codes have traditionally been widely used to characterize average concentrations within a limiting or target fuel assembly type. The average assembly concentrations are derived using a point depletion model via simple assembly-averaged fluxes and cross sections while accounting for a postulated power history of the target fuel assembly. A PWR validation study ${ }^{13}$ has been published to establish the expected performance for PWR- type fuel using these methods. The study concluded that using the latest available SCALE cross-sectional data, ${ }^{14}$ agreement with experimental PWR results was within $20 \%$ for most of the important nuclides for shielding problems.

A recent study 15 has quantified the relative contributions of both fission product and actinide radionuclides to the total dose exterior to several typical spent fuel casks. The results of this study can be summarized as follows:

1. The neutron dose rate primarily results from the concentration of ${ }^{244} \mathrm{Cm}$ for decay times less than 100 years.

2. The gamma ray dose for cooling times less than 100 years primarily results from the following isotopes, ${ }^{60} \mathrm{Co},{ }^{144} \mathrm{Pr},{ }^{134} \mathrm{Cs},{ }^{106} \mathrm{Rh},{ }^{154} \mathrm{Eu},{ }^{137} \mathrm{~m} \mathrm{Ba}$, and ${ }^{90} \mathrm{Y}$. All of these are fission products except for the ${ }^{60} \mathrm{Co}$, which is an activation product in the Inconel grid spacers and the steel end fittings from both BWR and PWR fuel elements.

While these results correspond to LEU PWR-type fuel assemblies, these general conclusions are not expected to change appreciably for MOX fuels. Of course, the amount of the ${ }^{60} \mathrm{Co}$ impurity can vary appreciably as well as the amount of structural steel. The initial presence of plutonium in the fresh fuel is expected to increase the relative amount of ${ }^{244} \mathrm{Cm}$ in the final assemblies as opposed to LWR fuel elements; however, the unshielded dose rates should continue to be almost entirely a result of gamma rays. In a typical spent fuel cask, the neutron dose rate can be important because of the use of large gamma ray shields (e.g., steel, lead), which are poor neutron shields in general. For this reason, a well-designed LWR spent fuel cask might not be an efficient design for MOX-type fuel assemblies.

\subsubsection{Spent Fuel Shielding Recommendations}

Measurement of isotopic concentrations for small samples of MOX-type spent fuel as well as doserate profiles for individual spent fuel assemblies would be useful data for extension of previous validation 
work. ${ }^{13,16}$ Additional measured data could be obtained using U.S. irradiated fuel from PWR or BWR irradiations, which were discussed earlier. These data would be important because of their use in establishing compliance of the MOX fuel cycle with the spent fuel standard. ${ }^{10}$

The isotopes listed above should certainly be included in an experimental isotopic determination, along with other materials that may be useful for other purposes. (See Ref. 13 for a complete list of nuclides that should be measured.)

Comparison of measured and calculated dose rates from a series of bare PWR fuel assembly experiments is reported in Ref. 16. In these experiments, spent fuel assemblies were measured both in a flooded and dry condition. The dry assembly measurements were performed in an underwater, air-filled diving bell apparatus that simulated an assembly-in-air configuration. Under these conditions, the neutron dose measurements are difficult because they are some 5 to 6 orders of magnitude lower than the gamma ray dose rates.

For multiple assemblies in a spent-fuel storage or transport cask configuration, the existence of dose rate measurements around the exterior surface of the cask provides very useful validation information about both the source magnitudes and the transport calculations for the loaded casks. Previously ORNL has obtained and analyzed a total of five different cask configurations for PWR fuel with both consolidated and unconsolidated fuel elements. ${ }^{16}$ This reference contains essentially complete information necessary for reanalysis of these experimental configurations. Similar experiments of this type would be very useful for validation of source term and shielding procedures for MOX-type fuel assemblies.

\section{REFERENCES}

1. Survey of Worldwide Light Water Reactor Experience with Mixed Uranium-Plutonium Oxide Fuel, Draft Letter Report, ORNL/MD/LTR-40, October 11, 1995. Predecisional publication, not available for public release.

2. Docket No. 50-244, Summary of Meeting Held on November 1, 1979, Letter from J. J. Shea, Nuclear Regulatory Commission, to Rochester Gas \& Electric Company, November 16, 1979.

3. Docket No. 50-244, Safety Evaluation and Notice of Issuance for Four MOX Assemblies, Letter from D. Ziemann, Nuclear Regulatory Commission, to L. D. White, Jr., Rochester Gas \& Electric Company.

4. Correspondence from J. Ortiz, Rochester Gas \& Electric Company, to S. E. Fisher, Lockheed Martin Energy Research Corp., Oak Ridge National Laboratory, February 18, 1997.

5. Quad Cities Nuclear and Fuel Performance Measurement, EPRI NP-3568, Electric Power Research Institute, prepared by General Electric Company, July 1984.

6. Gamma Scan Measurements at Quad Cities Nuclear Power Station Unit-1 Following Cycle 3, EPRI NP-2302-LD, Electric Power Research Institute, prepared by General Electric Company, Interim Report, March 1982.

7. Core Design and Operating Data for Cycles 1 and 2 of Quad Cities-1, EPRI NP-240, Electric Power Research Institute, prepared by General Electric Company, November 1976.

8. Core Design and Operating Data for Quad Cities 1 Cycle 3, EPRI NP-552, Electric Power Research Institute, prepared by General Electric Company, March 1983.

9. Design Guide for Packaging and Offsite Transportation of Nuclear Components, Special Assemblies, and Radioactive Materials Associated with the Nuclear Explosives and Weapons Safety Program, Chap. 5.0, "Radiation Shielding Aspects," U.S. Department of Energy Safety Guide 100, SG100-Rev. 1, November 7, 1994.

10. National Academy of Sciences, Management and Disposition of Excess Weapons Plutonium, National Academy Press, 1995.

11. A. G. Croff, ORIGEN2-A Revised and Updated Version of the Oak Ridge Isotope Generation and Depletion Code, ORNL-5621, Union Carbide Corp., Nuclear Div., Oak Ridge National Laboratory, July 1980.

12. O. W. Hermann and R. M. Westfall, "ORIGEN-S: SCALE System Module to Calculate Fuel Depletion, Actinide Transmutation, Fission Product Buildup and Decay, and Associated Radiation Source 
Terms," Sect. F7 of SCALE: A Modular Code System for Performing Standardized Computer Analyses for Licensing Evaluation, NUREG/CR-0200, Rev. 4 (ORNL/NUREG/CSD-2/R4), Vols. I, II, and III, draft November 1993. Available from Radiation Shielding Information Center, Lockheed Martin Energy Research Corp., Oak Ridge National Laboratory, as CCC-545.

13. O. W. Hermann, S. M. Bowman, M. C. Brady, and C. V. Parks, Validation of the SCALE System for PWR Spent Fuel Isotopic Composition Analyses, ORNL/TM-12667, Martin Marietta Energy Systems, Inc., Oak Ridge National Laboratory, March 1995.

14. SCALE: A Modular Code System for Performing Standardized Computer Analyses for Licensing Evaluation, NUREG/CR-0200, Rev. 4 (ORNL/NUREG/CSD-2/R4), Vols. I, II, and III, draft November 1993. Available from Radiation Shielding Information Center, Lockheed Martin Energy Research Corp., Oak Ridge National Laboratory, as CCC-545.

15. B. L. Broadhead et al., Investigation of Nuclide Importance to Functional Requirements Related to Transport and Long-Term Storage of LWR Spent Fuel, ORNL/TM-12742, Martin Marietta Energy Systems, Inc., Oak Ridge National Laboratory, June 1995.

16. B. L. Broadhead et al., Evaluation of Shielding Analysis Methods in Spent Fuel Cask Environments, EPRI TR-104329, Electric Power Research Institute, May 1995. 
Page Intentionally Blank 
ORNL/TM-13422

Dist. Category UC-523

\section{INTERNAL DISTRIBUTION}
1. S. L. Byerly
2. S. E. Fisher
3. E. C. Fox
4. S. R. Greene
5. G. T. Mays
6. G. E. Michaels
7-11. R. T. Primm III
12. D. G. O'Connor

\author{
13. P. L. Rittenhouse \\ 14. C. C. Southmayd \\ 15. D. J. Spellman \\ 16. D. L. Williams \\ 17. Central Research Library \\ 18-19. ORNL Laboratory Records (OSTI) \\ 20. ORNL Laboratory Records-RC
}

\section{EXTERNAL DISTRIBUTION}

21. D. J. Nulton, U.S. Department of Energy, MD-4, Forrestal Building, Room 6G-050, 1000 Independence Avenue SW, Washington, DC 20585.

22-26. P. T. Rhoads, U.S. Department of Energy, MD-3, Forrestal Building, Room 6G-050, 1000 Independence Avenue SW, Washington, DC 20585.

27. J. J. Buksa, Los Alamos National Laboratory, P.O. Box 1663, MS-F628, Los Alamos, NM 87545.

28. T. Barr, U.S. Department of Energy, EPG, Argonne National Laboratory, 9800 South Cass Avenue, Argonne, IL 60439.

\section{WWW DISTRIBUTION}

The FMDP Web site, with a list of other relevant topical reports, is located at the following URL:

http://www.ornl.gov/etd/FMDP/fmdpproc.htm 